
\title{
CS Resarach Square \\ Pharmacogenetic and Clinical Predictors of Ondansetron Failure in a Diverse Pediatric Oncology Population
}

\section{Shana Jacobs ( $\nabla$ ssjacobs@cnmc.org )}

Children's National Medical Center: Children's National Hospital https://orcid.org/0000-0002-0678-0621

\section{Jeffrey S Dome}

Children's National Medical Center: Children's National Hospital

Jiaxiang Gai

Children's National Medical Center: Children's National Hospital

\section{Andrea Gross}

National Institutes of Health

Elena Postell

Children's National Medical Center: Children's National Hospital

\section{Pamela Hinds}

Children's National Medical Center: Children's National Hospital

\section{Lionel Davenport}

Children's National Medical Center: Children's National Hospital

John $\mathrm{N}$ van den Anker

Children's National Medical Center: Children's National Hospital

\section{Catriona Mowbray}

Children's National Medical Center: Children's National Hospital

\section{Research Article}

Keywords: pediatric cancer, chemotherapy-induced nausea, pharmacogenomics, ondansetron

Posted Date: August 23rd, 2021

DOI: https://doi.org/10.21203/rs.3.rs-762220/v1

License: (c) (i) This work is licensed under a Creative Commons Attribution 4.0 International License. Read Full License

Version of Record: A version of this preprint was published at Supportive Care in Cancer on January 11th, 2022. See the published version at https://doi.org/10.1007/s00520-022-06818-9. 


\section{Abstract}

Purpose: Chemotherapy induced nausea and vomiting (CINV) is a frequently seen burdensome adverse event of cancer therapy. The 5-HT3 receptor antagonist ondansetron has improved the rates of CINV but, unfortunately, up to $30 \%$ of patients do not obtain satisfactory control. This study examined whether genetic variations in a relevant drug metabolizing enzyme (CYP2D6), transporter (ABCB1) or receptor (5HT3) were associated with ondansetron failure.

Methods: DNA was extracted from blood and used to genotype: ABCB1 (3435C>T (rs1045642) and G2677A/T (rs2032582)), 5-HT3RB (rs3758987 T>C and rs45460698 (delAAG/dupAAG)) and CYP2D6 variants. Ondansetron failure was determined by review of the medical records and by patient-reported outcomes (PROs).

Results: 129 patients were approached; 103 consented. Participants were less than 1 to 33 years (mean 6.85). $39.8 \%$ were female, $58.3 \%$ were White (22.3\% Black, $19.4 \%$ other); and $24.3 \%$ were Hispanic. A majority had leukemia or lymphoma, and $41(39.8 \%)$ met the definition of ondansetron failure. Of variants tested, rs45460698 independently showed a significant difference in risk of ondansetron failure between a mutant (any deletion) and normal allele ( $p=0.0281$, OR 2.67). Age and BMI were both predictive of ondansetron failure (Age > 12 (OR 1.12, $p=0.0012)$ and higher BMI (OR 1.13, $p=0.0119)$ ). In multivariate analysis, age $>12$ was highly predictive of ondansetron failure (OR 7.108, $p=0.0008$ ). rs 45460698 was predictive when combined with an increased nausea phenotype variant of rs1045642 (OR 3.45, $p=0.0426$ ).

Conclusion: Select phenotypes of 5-HT3RB and ABCB1, age, and potentially BMI can help predict increased risk for $\mathrm{CINV}$ in a diverse pediatric oncology population.

\section{Background}

Despite dramatic improvements in survival in pediatric cancer over the past 50 years ${ }^{1}$ many patients experience significant treatment-related toxicities. Chemotherapy induced nausea and vomiting (CINV) is one of the most common and distressing complications of cancer therapy ${ }^{2}$. The widespread use of the 5HT3 receptor antagonist ondansetron has improved the rates of CINV but up to $30 \%$ of patients still do not obtain satisfactory control of this bothersome symptom ${ }^{1,3}$. While the degree of CINV has been shown to be influenced by a wide variety of factors including patient age, race, sex, BMI, type of cancer, presence of metastases and type of chemotherapeutic agent ${ }^{4}$, there is also a growing body of evidence that genetic variations in how ondansetron is handled may determine an individual patient's responsiveness to this medication. This body of research is primarily focused on three main areas: (1) genetic variations in hepatic metabolism of ondansetron (2) the mechanism by which the drug is transported to and from sanctuary sites, such as the CNS and (3) polymorphisms in the 5-HT3 receptor itself.

In general, 5-HT3 receptor antagonists are metabolized to their inactive form in the liver through the cytochrome P450 system ${ }^{3,5,6}$ Those with no active CYP2D6 genes are considered poor metabolizers (PM), 
while those with 3 or more active genes are ultra-rapid metabolizers (UR) ${ }^{3}$. In a Caucasian population, the prevalence of poor and ultra-rapid metabolizers are estimated at $12 \%$ and $2 \%$, respectively while some more recent population studies report 3-4\% prevalence of UR and 3-6\% for PM in African American, American Latinos and Europeans ${ }^{7,5}$ Several studies in adult cancer patients have demonstrated that UR metabolizers are less likely to maintain therapeutic drug levels and therefore are at increased risk for ondansetron failure ${ }^{8,9}$. Ondansetron is primarily metabolized into its inactive form by CYP2D 6 but is also partially degraded by CYP3A4. Perhaps more significantly, granisetron, another 5-HT3 receptor antagonist, is metabolized almost entirely by CYP3A4 which could explain why many patients who fail to respond to ondansetron have been shown to have a good response to granisetron despite their similar mechanism of action ${ }^{5}$.

Genetically dependent alterations in the manner by which 5-HT3 receptor antagonists are transported across cell membranes may also influence a patient's responsiveness to these drugs. P-glycoprotein (PGP), an ATP dependent drug transporter, has been shown to be responsible for the efflux of a wide range of medications ${ }^{10,4,11} 12,132-72-71-61-6$ and the gene that encodes it goes by several names including adenosine triphosphate-binding cassette subfamily $\mathrm{B}$ member 1 ( $A B C B 1)$ and human multidrug resistance gene (MDR-1). Single nucleotide polymorphisms (SNPs) in two exons of $A B C B 1$ have been correlated with altered functioning of the PGP transporter: $3435 \mathrm{C}>\mathrm{T}$ and G2677A/T. There have been several studies evaluating the association between these SNPs and control of CINV treated with 5-HT3 receptor antagonists, showing that those with the TT genotype have the best response to ondansetron and those with the CG haplotype have increased risk of ondansetron failure 101114151617 . Other studies have shown conflicting importance of these SNPs on expression of PGP in relation to metabolism of other drugs 1213 .

The 5-HT3 receptor (5HT3R) is a pentameric ligand gated ion channel ${ }^{18}{ }^{19}$ which may contain genetic polymorphisms that contribute to variations in responsiveness to $5-\mathrm{HT} 3$ receptor antagonists. There are five subunits that combine in various permutations to form the channel; research to date has primarily focused on variations in the $5-H T 3 R A$ and $B$ subunits ${ }^{19}$. In the $5-H T 3 R B$ gene in adult cancer patients receiving chemotherapy, patients that were homozygous for a deletion from position -100-102 of the gene resulting in deletion of three base pairs (AAG) were found to have significantly increased nausea/vomiting when compared with patients without this allele ${ }^{18}$. Intriguingly, there appeared to be a gene dose effect with those patients homozygous for the deletion having the worst nausea/vomiting, those homozygous for the wild type gene with the least symptoms and those heterozygous for the deletion with scores in between the two groups ${ }^{18}$. Interestingly, Kaiser et al examined 21 polymorphisms in the 5 -HT3A gene in the same group of cancer patients and found no correlation between any of the polymorphisms and reported episodes of nausea and vomiting 20

Based on this evidence that genomic differences may be in part responsible for the nearly $30 \%$ of patients that are refractory to therapy with ondansetron ${ }^{20}$, we examined whether polymorphisms in CYP2D6, $A B C B 1$ and $5-H T 3 R B$ genes were associated with ondansetron failure. To our knowledge, this is the first 
study looking at all of these polymorphisms together to predict ondansetron failure in an ethnically diverse pediatric cancer population.

This study is also unique in incorporating the Pediatric Patient -Reported Outcomes version of the Common Terminology Criteria for Adverse events (Ped-PRO-CTCAE, https://healthcaredelivery.cancer.gov/pro-ctcae/instrument-ped.html). This system was developed to collect subjective symptom data directly from the child and their proxy during cancer treatment ${ }^{21}, 22$. In this paper we report on the nausea item asked prospectively over 4 treatment cycles to grade the frequency, severity, and interference of nausea.

\section{Methods}

\section{Patient recruitment and enrollment}

All patients with a new diagnosis of cancer of any type, expected to receive chemotherapy at a single tertiary free-standing children's hospital were approached for participation within 3 months of their diagnosis. Patients were approached during clinic visits or inpatient admissions and informed consent/assent was obtained per institutional guidelines. This was part of a larger study investigating pharmacogenetic variation and multiple toxicities. Patient demographics including gender and age, diagnosis, and treatment plan were collected from the medical record. Race/ ethnicity data was collected directly from the patient or parent. This report focuses only on failure of ondansetron treatment. This study was approved by the institutional review board.

\section{Molecular analysis}

All patients had blood drawn at the time of enrollment or when their white blood count was sufficient for DNA extraction. DNA was extracted from blood using Qiagen Qiasymphony. Polymorphisms ABCB1 3435C>T (rs1045642) (probe1), G2677A/T (rs2032582) (probe 2) and 5-HT3RB, (rs3758987 T>C) (probe3) were genotyped using commercially available pre-designed Taqman assays. The polymorphism rs45460698 on the 5-HT3RB gene (delAAG/dupAAG, probe 4) was genotyped by a custom Taqman assay.

All Taqman assays were purchased from ThermoFisher Scientific and analyzed on the Applied Biosystems Quantstudio 3Data using ABI Quanstudio Design and Analysis software. CYP2D6 was genotyped using the FDA approved Luminex kit XTAG ${ }^{8}$ CYP2D6 Kit v323. As a quality control a Positive and Negative control were run with each set of samples. The following star genotypes were called $(* 2, * 3, * 4, \star 5, * 6, * 7, * 8$, $\star 9, * 10, * 11, * 15, * 17, \star 29, * 35, * 41$, DUP) and phenotype assigned ${ }^{24}$. In the case of duplications, not all the duplication phenotypes could not be identified. Variants were phenotypically labeled as being at greater or lesser risk of ondansetron failure based on published work and recommendations from PharmGKB website (https://www.pharmgkb.org/clinicalAnnotation/1183632195).

\section{Chart review and Patient Reported Outcomes}


Ondansetron failure was ascertained by review of the medical record using a systemized approach and by analysis of patient reported outcomes. The electronic medical record was reviewed for each patient over at least 4 treatment cycles for the development of ondansetron failure, which was defined as a) switch to granisetron instead of ondansetron, $\mathrm{OR}$ b) use of ondansetron plus 3 other antiemetic medications around the clock, OR c) the documentation of severe nausea in the medical record despite taking ondansetron. Study participants aged 7-18y and proxy reporters for patients 5-18y completed the Pediatric or Proxy PROCTCAE as appropriate at the beginning of and during multiple rounds of chemotherapy (up to 4 times). Participants were asked "in the past 7 days, how bad was your nausea (feeling sick to your stomach)"? Those who answered as having nausea (i.e. reported frequency more than "never") "sometimes" or higher with a severity "bad" more than a "little bad" that caused interference other than "not at all" and interference of "some" or more) by patient or proxy were also considered to have ondansetron failure. The PRO data were collected separately from the review of the medical record.

\section{Statistical analysis}

Categorical variables are summarized by counts and percentages, while continuous variables are reported as mean \pm SD. Categorical data were compared by contingency table analysis (chi-square or fisher's exact), and continuous data were compared by unpaired t-tests.

A series of univariate logistic regression analyses were performed to assess individual variable associations with ondansetron failure. A final multivariable logistic regression model was built to assess variable associations with ondansetron failure adjusting for age and race. Any variables with univariate significance less than 0.2 were selected into the multivariable model. Backward selection method was applied to select the final model with a significance threshold of 0.05 . Age and race were forced into the final model.

Statistical analyses were performed using SAS 9.4 (SAS Institute, Cary, NC) and R v4.02 ${ }^{25}$.

Chi square or Fisher's exact test was used to test association between ondansetron failure and each polymorphism investigated (CYP2D6, rs45460698 and rs3758987 5-HT3RB (probe4 and 3), and rs1045642 (probe1) and rs203258 (probe2) on ABCB1 (3435C>T and G2677A/T).

Univariant and multivariate analyses were conducted.

\section{Results}

One hundred twenty-nine patients were approached between 03/20/2017 and 03/14/19, and 103 consented (80\%). Enrolled participants ranged in age from less than 1 to 33 years (mean 6.85). In selfdefined demographic descriptions (Table 1), 39.8\% were female, $58.3 \%$ were white with $22.3 \%$ black and $19.4 \%$ other (including multiracial) and $24.3 \%$ were Hispanic (of note most of those identifying as Hispanic also identified as White). A majority (57.3\%) had leukemia or lymphoma, $20.4 \%$ had a solid tumor and $7.8 \%$ had a CNS tumor. 
Forty one (39.8\%) patients met the definition of ondansetron failure either by review of the EMR ((a) switch to granisetron instead of ondansetron (14 patients) OR b) use of ondansetron plus 3 other antiemetic medications around the clock (22 patients) OR c) the documentation of severe nausea in the medical record despite taking ondansetron (26 patients)) OR by Ped PROCTCAE reported nausea (12 patients). The criteria by which patients met the definition is shown in table 2 . Variants previously associated with increased risk of nausea and vomiting were found in both groups (Table 3). Only probe 4 (rs45460698 in 5-HT3RB) independently showed a significant difference in increased risk of ondansetron failure between mutant (any deletion) and normal allele (Table 3, $p=0.0281$ ) with odds ratio 2.67 (Table 4, p=0.03).

Nine of $103(8.7 \%)$ patients had a CYP2D6 polymorphism reported as associated with ondansetron failure$5(5 \%)$ were ultra-rapid metabolizers and $4(4 \%)$ were poor metabolizers but the rate of ondansetron failure was not statistically different between these groups (Table 3 and 4 ).

Of the 103 patients who consented 64 were ineligible for Ped PRO-CTCAE due to age (patient $<5$ or $>18$ years old) or language (Arabic). One patient received chemotherapy at a site without staff to administer study questionnaires. Thirty patients and 32 proxies completed the Peds PRO-CTCAE nausea item at least once, 25 were dyads (patient and proxy), 13 responses were from either a patient or proxy (missing data due to non-English-speaking parents or child under 7 years. Results of the PRO reports are shown in Table 5. Four patients were identified as having severe nausea by PRO reports alone and were not discovered by review of the medical record (supplementary table).

Several clinical variables were analyzed to determine their role in developing severe nausea or ondansetron failure. Age and BMI were both found to be predictive of ondansetron failure with higher age (greater than 12 (OR 1.12, $p=0.0012)$ and higher BMI (OR 1.13, $p=0.0119)$ being associated with higher rates of ondansetron failure (Table 1, Table 3). Gender, and ethnicity showed no differences (Table 4). Diagnosis was also predictive, with highest rates of ondansetron failure being seen in patients with CNS tumors and lowest rates in kidney tumors (Table1).

In multivariate analysis (Table 6), age was still highly predictive of ondansetron failure with age $>12$ having higher rates of ondansetron failure than younger children (OR 7.108, $p=0.0008)$. Race and $B M I$ were not significant. Probe 4 (rs45460698 on 5-HT3RB) was predictive of ondansetron failure when combined with increased nausea phenotype variant of probe 2 (G2677A/T (rs2032582) on ABCB1) (OR $3.45, p=0.0426)$.

\section{Discussion}

This analysis incorporates medical record toxicities, genetic testing and PROs to develop a clearer picture of the risk factors involved in increased chemotherapy induced nausea and vomiting, and specifically in ondansetron failure. Our findings demonstrated that the polymorphism rs45460698 on the 5-HT3RB gene was predictive of ondansetron failure in both univariate and multivariate analysis, particularly in combination with rs 1045642 on ABCB1 in multivariate analysis. Importantly, the other probes we studied did not independently predict ondansetron failure or worse nausea. Of note, despite previous literature 
suggesting a role of CYP2D6 polymorphisms in ondansetron metabolism ${ }^{26,27}$, these polymorphisms did not prove predictive in our study.

Risk factors for chemotherapy related nausea and vomiting are not as well described in pediatrics as in adult cancer patients, and many adult factors (age, history of pregnancy related nausea) are not relevant ${ }^{28}$. In our study, age greater than 12 was highly predictive of ondansetron failure. This is similar to the findings of several prior studies that found older age associated with worse nausea $29,30,31$, but differs from the recent findings of Dupuis et al for pediatric patients receiving highly emetogenic chemotherapy in which age was not significant ${ }^{32}$. Additionally, in Dupuis' study, non-white race was found to have worse chemotherapy related nausea, while we found a trend towards less nausea among African Americans, though we did not group all non-white patients together as they did. Additionally, differences in definition of nausea and our focus on ondansetron failure may have explained some of the differences in findings.

This study is unique in the complete picture of assessing toxicity that we used, drawing on medical record documentation, medication use, and patient reported outcomes. This is the first study that we know of that combined all of these approaches. Of note, we examined a diverse group of patients in terms of race and ethnicity and diagnosis. Many investigations of pharmacogenomics have looked at predominantly white or otherwise more homogeneous populations, while our population is more representative of the country as a whole.

The limitation of the analysis is that the sample size is small, and therefore there may have been lack of sufficient statistical power to detect some of the associations. Additionally, while the diversity of the sample is an asset in many ways, it also limits the conclusions we can make due to multiple confounders in terms of treatments and antiemetic regimens used. Finally, our definition of ondansetron failure may have been too broad. Nausea is an extremely multifactorial symptom and we may have included patients who had higher than expected nausea but still may have responded well to ondansetron.

This study provides preliminary information about the role of pharmacogenetics in metabolism of ondansetron and in management of chemotherapy induced nausea and vomiting in pediatric cancer patients. Specifically, future studies should look at deletions at rs45460698 on 5-HT3RB, possibly in combination with genotypes other than AA at rs2032582 in ABCB1. Ideally, we would be able to identify up front a group of patients at risk for significant nausea and vomiting and ondansetron failure who would benefit from early switching from ondansetron to an alternative 5-HT3 receptor antagonist, and the use of additional antiemetics.

\section{Declarations}

\section{Funding}

This project was supported by Award Numbers UL1TR001876 and KL2TR001877 from the NIH National Center for Advancing Translational Sciences, a Hyundai Hope on Wheels Impact Grant 2017, and funds 
from the Children's National Heroes Curing Childhood Cancer Gala.

Its contents are solely the responsibility of the authors and do not necessarily represent the official views of the National Center for advancing Translational Sciences or the National Institutes of Health

Conflicts of interest: authors have nothing to disclose

Availability of data and material: Data is available upon request

Authors' contributions: Conceptualization: Shana Jacobs, Jeffrey Dome, Catriona Mowbray, Andrea Gross, Pamela Hinds, and John van den Anker. Methodology: Catriona Mowbray, Elena Postell. Analysis and Investigation: Shana Jacobs, Catriona Mowbray, Jiaxiang Gai. Writing original draft and preparation: Shana Jacobs, Catriona Mowbray, Jiaxiang Gai. Writing - review and editing: all authors

Ethics approval: This study was approved by the Institutional Review Board at Children's National Hospital.

Consent to participate: Parents (for children less than 18) or participants provided informed consent according to institutional guidelines. Patients 7 to 17 also provided assent.

\section{Consent for publication: N/A}

\section{References}

1. Smith MA, Seibel NL, Altekruse SF, et al. Outcomes for Children and Adolescents With Cancer: Challenges for the Twenty-First Century. J Clin Oncol. Published online April 19, 2010. doi:10.1200/JCO.2009.27.0421

2. Hickok JT, Roscoe JA, Morrow GR, King DK, Atkins JN, Fitch TR. Nausea and emesis remain significant problems of chemotherapy despite prophylaxis with 5-hydroxytryptamine-3 antiemetics. Cancer. 2003;97(11):2880-2886. doi:https://doi.org/10.1002/cncr.11408

3. de Wit R, Aapro M, Blower PR. Is there a pharmacological basis for differences in 5-HT3-receptor antagonist efficacy in refractory patients? Cancer Chemother Pharmacol. 2005;56(3):231-238. doi:10.1007/s00280-005-1033-0

4. Laugsand EA, Fladvad T, Skorpen F, et al. Clinical and genetic factors associated with nausea and vomiting in cancer patients receiving opioids. Eur J Cancer. 2011;47(11):1682-1691. doi:10.1016/j.ejca.2011.04.014

5. Aapro M. Optimising antiemetic therapy: what are the problems and how can they be overcome? Curr Med Res Opin. 2005;21(6):885-897. doi:10.1185/030079905X46313

6. Kaiser R, Sezer O, Papies A, et al. Patient-Tailored Antiemetic Treatment With 5-Hydroxytryptamine Type 3 Receptor Antagonists According to Cytochrome P-450 2D6 Genotypes. J Clin Oncol. 2002;20(12):2805-2811. doi:10.1200/JC0.2002.09.064

7. Huddart R, Fohner AE, Whirl-Carrillo M, et al. Standardized Biogeographic Grouping System for Annotating Populations in Pharmacogenetic Research. Clin Pharmacol Ther. 2019;105(5):1256-1262. 
doi:https://doi.org/10.1002/cpt.1322

8. Bell GC, Caudle KE, Whirl-Carrillo M, et al. Clinical Pharmacogenetics Implementation Consortium (CPIC) Guideline for CYP2D6 Genotype and Use of Ondansetron and Tropisetron. Clin Pharmacol Ther. 2017;102(2):213-218. doi:10.1002/cpt.598

9. Aka I, Bernal CJ, Carroll R, Maxwell-Horn A, Oshikoya KA, VanDriest SL. Clinical Pharmacogenetics of Cytochrome P450-Associated Drugs in Children. J Pers Med Basel. 2017;7(4):14.

doi:http://dx.doi.org.proxygw.wrlc.org/10.3390/jpm7040014

10. Babaoglu MO, Bayar B, Aynacioglu AS, et al. Association of the ABCB1 3435C>T polymorphism with antiemetic efficacy of 5-hydroxytryptamine type 3 antagonists. Clin Pharmacol Ther. 2005;78(6):619626. doi:https://doi.org/10.1016/j.clpt.2005.08.015

11. He H-R, Liu P, He G-H, et al. Association between reduced folate carrier G80A polymorphism and methotrexate toxicity in childhood acute lymphoblastic leukemia: a meta-analysis. Leuk Lymphoma. 2014;55(12):2793-2800. doi:10.3109/10428194.2014.898761

12. Horinouchi M, Sakaeda T, Nakamura T, Morita Y, al et. Significant genetic linkage of MDR1 polymorphisms at positions 3435 and 2677: Functional relevance to pharmacokinetics of digoxin. Pharm Res N Y. 2002;19(10):1581-1585.

13. Leschziner GD, Andrew T, Pirmohamed M, Johnson MR. ABCB1 genotype and PGP expression, function and therapeutic drug response: a critical review and recommendations for future research. Pharmacogenomics J. 2007;7(3):154-179. doi:10.1038/sj.tpj.6500413

14. Brinkmann U. Functional polymorphisms of the human multidrug resistance (MDR1) gene: correlation with P glycoprotein expression and activity in vivo. Novartis Found Symp. 2002;243:207-210; discussion 210-212, 231-235. doi:10.1002/0470846356.ch15

15. He H, Yin J-Y, Xu Y-J, et al. Association of ABCB1 Polymorphisms With the Efficacy of Ondansetron in Chemotherapy-induced Nausea and Vomiting. Clin Ther. 2014;36(8):1242-1252.e2. doi:10.1016/j.clinthera.2014.06.016

16. Choi EM, Lee MG, Lee SH, Choi KW, Choi SH. Association of ABCB1 polymorphisms with the efficacy of ondansetron for postoperative nausea and vomiting: Association of ABCB1 polymorphisms with the efficacy of ondansetron. Anaesthesia. 2010;65(10):996-1000. doi:10.1111/j.13652044.2010.06476.x

17. López-Morales P, Flores-Funes D, Sánchez-Migallón EG, Lirón-Ruiz RJ, Aguayo-Albasini JL. Genetic Factors Associated with Postoperative Nausea and Vomiting: a Systematic Review. J Gastrointest Surg. 2018;22(9):1645-1651. doi:10.1007/s11605-018-3788-8

18. Tremblay P-B, Kaiser R, Sezer O, et al. Variations in the 5-Hydroxytryptamine Type 3B Receptor Gene as Predictors of the Efficacy of Antiemetic Treatment in Cancer Patients. J Clin Oncol. 2003;21(11):21472155. doi:10.1200/JC0.2003.05.164

19. Niesler B. Serotonin type 3 receptor genes: HTR3A, B, C, D, E. Pharmacogenomics Lond. 2008;9(5):501504. doi:http://dx.doi.org.proxygw.wrlc.org/10.2217/14622416.9.5.501 
20. Kaiser, R, Sezer, O, Possinger K, Roots I, Brockmoller J. Investigation of the association between 5HT3A receptor gene polymorphisms and efficiency of antiemetic treatment with 5-HT3 receptor antagonists. Pharmacogenetics. 2004;14(5):271-278.

21. Reeve BB, Withycombe JS, Baker JN, et al. The first step to integrating the child's voice in adverse event reporting in oncology trials: A content validation study among pediatric oncology clinicians. Pediatr Blood Cancer. 2013;60(7):1231-1236. doi:10.1002/pbc.24463

22. Reeve BB, McFatrich M, Pinheiro LC, et al. Eliciting the child's voice in adverse event reporting in oncology trials: Cognitive interview findings from the Pediatric Patient-Reported Outcomes version of the Common Terminology Criteria for Adverse Events initiative. Pediatr Blood Cancer. 2017;64(3):e26261. doi:https://doi.org/10.1002/pbc.26261

23. xTAG CYP2D6 kit v3. Luminex. Published 2020 2006. Accessed October 18, 2020. https://www.luminexcorp.com/cyp2d6/)

24. Owen RP, Sangkuhl K, Klein TE, Altman RB. Cytochrome P450 2D6. Pharmacogenet Genomics. 2009;19(7):559-562. doi:10.1097/FPC.0b013e32832e0e97

25. R: A language and environment for statistical computing. The R Project for Statistical computing. Accessed October 14, 2020. https://www.r-project.org

26. Bell GC, Caudle KE, Whirl-Carrillo M, et al. Clinical Pharmacogenetics Implementation Consortium (CPIC) guideline for CYP2D6 genotype and use of ondansetron and tropisetron. Clin Pharmacol Ther. 2017;102(2):213-218. doi:https://doi.org/10.1002/cpt.598

27. Niewiński P, Wojciechowski R, Śliwiński M, et al. CYP2D6 basic genotyping as a potential tool to improve antiemetic efficacy of ondansetron in prophylaxis of postoperative nausea and vomiting. $A d v$ Clin Exp Med. 2018;27(11):1499-1503. doi:10.17219/acem/69451

28. Sherani F, Boston C, Mba N. Latest Update on Prevention of Acute Chemotherapy-Induced Nausea and Vomiting in Pediatric Cancer Patients. Curr Oncol Rep. 2019;21(10):89. doi:10.1007/s11912-019-08400

29. LeBaron S, Zeltzer LK, LeBaron C, Scott SE, Zeltzer PM. Chemotherapy side effects in pediatric oncology patients: drugs, age, and sex as risk factors. Med Pediatr Oncol. 1988;16(4):263-268. doi:10.1002/mpo.2950160408

30. Holdsworth MT, Raisch DW, Frost J. Acute and delayed nausea and emesis control in pediatric oncology patients. Cancer. 2006;106(4):931-940. doi:10.1002/cncr.21631

31. Freedman JL, Faerber J, Kang TI, et al. Predictors of antiemetic alteration in pediatric acute myeloid leukemia. Pediatr Blood Cancer. 2014;61(10):1798-1805. doi:10.1002/pbc.25108

32. Dupuis LL, Tamura RN, Kelly KM, et al. Risk factors for chemotherapy-induced nausea in pediatric patients receiving highly emetogenic chemotherapy. Pediatr Blood Cancer. 2019;66(4):e27584. doi:10.1002/pbc. 27584

\section{Tables}

Table 1 Demographic information 


\begin{tabular}{|lllll|}
\hline Variable & Ondansetron Failure $\mathrm{n}=\mathbf{4 1}$ & Not $\mathrm{n}=\mathbf{6 2}$ & Overall $\mathbf{n}=\mathbf{1 0 3}$ & P Value \\
\hline Age Mean (SD) & $9.61(7.81)$ & $5.03(4.84)$ & $6.85(6.56)$ & 0.0004 \\
\hline Older than 12years & $17(41.5 \%)$ & $5(8.1 \%)$ & $22(21.4 \%)$ & 0.0001 \\
\hline BMI Mean (SD) & $20.34(5.11)$ & $17.8(4.06)$ & $18.81(4.76)$ & 0.0062 \\
\hline Female Sex (\%) & $17(41.5 \%)$ & $24(38.7 \%)$ & $41(39.8 \%)$ & 0.7799 \\
\hline Ethnicity Hispanic & $11(26.8 \%)$ & $14(22.6 \%)$ & $25(24.3 \%)$ & 0.6225 \\
\hline Race & & & & 0.0763 \\
\hline Black or AA & $5(12.2 \%)$ & $18(29.0 \%)$ & $23(22.3 \%)$ & \\
\hline Other* & $11(26.8 \%)$ & $9(14.5 \%)$ & $20(19.4 \%)$ & \\
\hline White & $25(61 \%)$ & $35(56.5 \%)$ & $60(58.3 \%)$ & \\
\hline Diagnosis & & & & 0.0448 \\
\hline AML & $3(7.3 \%)$ & $4(6.5 \%)$ & $7(6.8 \%)$ & \\
\hline${ }^{1}$ CNS & $6(14.6 \%)$ & $2(3.2 \%)$ & $8(7.8 \%)$ & \\
\hline${ }^{2}$ Kidney tumor & $0(0 \%)$ & $7(11.3 \%)$ & $7(6.8 \%)$ & \\
\hline${ }^{3}$ ALL or ALLy & $14(34.1 \%)$ & $28(45.2 \%)$ & $42(40.8 \%)$ & \\
\hline${ }^{4}$ Lymphoma & $4(9.8 \%)$ & $6(9.7 \%)$ & $10(9.7 \%)$ & \\
\hline Neuroblastoma & $2(4.9 \%)$ & $6(9.7 \%)$ & $8(7.8 \%)$ & \\
\hline${ }^{5}$ Solid tumor & $12(29.3 \%)$ & $9(14.5 \%)$ & $21(20.4 \%)$ & \\
\hline
\end{tabular}

Note. Categorical variables are summarized by counts and percentages, while continuous variables are reported as mean \pm SD.

${ }^{1}$ CNS includes Atypical Teratoid/Rhabdoid tumor, Embryonal, Medulloblastoma,

${ }^{2}$ Kidney tumor includes Wilms tumor, clear cell carcinoma of kidney,

${ }^{\circledR A L L}$ or ALLy includes all B and T cell Lymphoblastic leukemia/lymphoma

${ }^{4}$ Lymphoma includes Hodgkins, peripheral Tcell lymphoma, diffuse large B cell lymphoma, anaplastic large cell lymphoma

${ }^{5}$ Solid tumor includes Ewing sarcoma, hepatoblastoma, high grade spindle cell sarcoma, rhabdomyosarcoma, MPNST, Osteosarcoma, sex cord stromal tumor. 
*Other - mixed race, Asian/Pacific Islander, and "other" as chosen by respondent

The $\mathrm{p}$ values for race and diagnosis are generated from Chi-square tests of homogeneity, it is testing if the groups are different between the two population (failure vs non failure).

Table 2 Number of individual study IDs that met each definition at any point in first 4 treatment cycles

\begin{tabular}{|lllll|}
\hline & $\begin{array}{l}\text { Switched to } \\
\text { granisetron }\end{array}$ & $\begin{array}{l}\text { Needed 3 } \\
\text { antiemetics }\end{array}$ & $\begin{array}{l}\text { Severe } \\
\text { nausea }\end{array}$ & $\begin{array}{l}\text { PRO } \\
\text { definition }\end{array}$ \\
\hline $\begin{array}{l}\text { Switched to } \\
\text { granisetron }\end{array}$ & 14 & 7 & 10 & 4 \\
\hline Needed 3 antiemetics & 7 & 22 & 14 & 5 \\
\hline Severe nausea & 10 & 14 & 26 & 8 \\
\hline PRO definition & 5 & 5 & 7 & 12 \\
\hline
\end{tabular}

Definitions

Needed granisetron - patient received granisetron documented in medical record (T1-T4)

Needed 3 antiemetics - patient received 3 or more antiemetics on top of ondansetron or granisetron (T1T4)

Severe nausea definition - that term documented in note or admission for N/V or N/V prolonging hospitalization (T1-T4)

PRO definition - nausea frequency more than "never" (2-4) ,AND severity more than a "little bad" (3-4) AND interference more than "not at all" (2-4) by patient or proxy (T1-T5, timing of surveys to match treatment cycles 1-4)

\section{Table 3 Genetic distributions}




\begin{tabular}{|c|c|c|c|c|}
\hline Variable & $\begin{array}{l}\text { Ondansetron } \\
\text { Failure } \\
\mathrm{n}=41\end{array}$ & $\begin{array}{l}\text { Not } \\
n=62\end{array}$ & $\begin{array}{l}\text { Overall } \\
n=103\end{array}$ & $\begin{array}{l}\mathrm{P} \\
\text { Value }\end{array}$ \\
\hline CYP2D6_polymorphisms & & & & 0.5893 \\
\hline Duplications of unknown phenotype & 1 & 4 & $5(5.1 \%)$ & \\
\hline Extensive and Intermediate metabolizers & $37(92.5 \%)$ & $\begin{array}{l}52 \\
(89.7 \%)\end{array}$ & $89(90.8 \%)$ & \\
\hline Poor metabolizer & $2(5 \%)$ & $2(3.4 \%)$ & $4(4.1 \%)$ & \\
\hline Ultrarapid metabolizer & $1(2.5 \%)$ & $4(6.9 \%)$ & $5(5.1 \%)$ & \\
\hline Probe1: ABCB1 3435C>T (rs1045642) & $\mathrm{n}=41$ & $n=62$ & & 0.5971 \\
\hline decreased risk of N/V (AA) & $9(22 \%)$ & $\begin{array}{l}11 \\
(17.7 \%)\end{array}$ & $20(19.4 \%)$ & \\
\hline increased risk of N/V (AG/GG) & $32(78 \%)$ & $\begin{array}{l}51 \\
(82.3 \%)\end{array}$ & $83(80.6 \%)$ & \\
\hline Probe 2: ABCB1 G2677A/T (rs2032582) & $\mathrm{n}=41$ & $n=62$ & & 0.5369 \\
\hline decreased risk of $N / V(A A)$ & $6(14.6 \%)$ & $\begin{array}{l}12 \\
(19.4 \%)\end{array}$ & $18(17.5 \%)$ & \\
\hline increased risk of N/V (CA/TA/TC) & 35 (85.4\%) & $\begin{array}{l}50 \\
(80.6 \%)\end{array}$ & $85(82.5 \%)$ & \\
\hline Probe 3: 5-HT3RB, T>C (rs3758987) & $\mathrm{n}=41$ & $n=62$ & & 0.2372 \\
\hline decreased risk of $\mathrm{N} / \mathrm{V}(\mathrm{TT})$ & $26(63.4 \%)$ & $\begin{array}{l}32 \\
(51.6 \%)\end{array}$ & $58(56.3 \%)$ & \\
\hline increased risk of N/V (CC/CT) & $15(36.6 \%)$ & $\begin{array}{l}30 \\
(48.4 \%)\end{array}$ & $45(43.7 \%)$ & \\
\hline $\begin{array}{l}\text { Probe 4: on 5-HT3RB delAAG/dupAAG } \\
\text { (rs45460698) }\end{array}$ & $n=41$ & $n=62$ & & 0.0281 \\
\hline decreased risk of N/V (no del) & $25(61 \%)$ & $\begin{array}{l}50 \\
(80.6 \%)\end{array}$ & $75(72.8 \%)$ & \\
\hline increased risk of N/V (del or het) & $16(39 \%)$ & $\begin{array}{l}12 \\
(19.4 \%)\end{array}$ & $28(27.2 \%)$ & \\
\hline
\end{tabular}

note. Chi square test. rs refers to specific SNP. Abbreviations deletion (del), heterozygous (het) N/V nausea/vomiting 


\begin{tabular}{|lllll|}
\hline Variable & Odds ratio & Lower & Upper & P Value \\
\hline CYP2D6_PM & 1.405 & 0.189 & 10.434 & 0.4531 \\
\hline CYP2D6_UR & 0.351 & 0.038 & 3.272 & 0.3226 \\
\hline Probe1 increased N/V risk & 0.767 & 0.286 & 2.055 & 0.5976 \\
\hline Probe2 increased N/V risk & 1.400 & 0.480 & 4.085 & 0.5381 \\
\hline Probe3 increased N/V risk & 0.615 & 0.274 & 1.380 & 0.2386 \\
\hline Probe4 increased N/V risk & 2.667 & 1.096 & 6.488 & 0.0306 \\
\hline Probe 4 Any Del \& Probe 1 increased & 1.907 & 0.725 & 5.015 & 0.1909 \\
\hline Probe 4 Any Del \& Probe 2 increased & 3.500 & 1.308 & 9.361 & 0.0126 \\
\hline Probe 4 Any Del \& Probe 3 increased & 1.525 & 0.093 & 25.087 & 0.7677 \\
\hline Age $\geq 12$ vs < 12 & 1.125 & 1.048 & 1.209 & 0.0012 \\
\hline BMI & 1.137 & 1.029 & 1.257 & 0.0119 \\
\hline Female & 1.122 & 0.502 & 2.507 & 0.7799 \\
\hline Hispanic & 1.257 & 0.505 & 3.129 & 0.6228 \\
\hline Race Black vs. not black & 0.227 & 0.060 & 0.856 & 0.0329 \\
\hline Race White vs. not white & 0.584 & 0.211 & 1.620 & 0.6340 \\
\hline
\end{tabular}

Note. Univariate logistic regression was used.

Table 5 Number of responses at each timepoint for each PROCTCAE item by patient and proxy 

Proxy + PT $\quad$ T1
T2
T3
T4
T5
T6
response

Proxy Pt Proxy Pt Proxy Pt Proxy Pt Proxy Pt Proxy Pt

\section{Frequency}

\begin{tabular}{lllllllllllll}
\hline "never" & 22 & 21 & 7 & 21 & 15 & 21 & 11 & 21 & 18 & 21 & 23 & 21 \\
$\begin{array}{l}2 \\
\text { "sometimes" }\end{array}$ & 7 & 7 & 18 & 7 & 11 & 7 & 11 & 7 & 4 & 7 & 5 & 7 \\
$\begin{array}{l}3 \text { "most of } \\
\text { the time" }\end{array}$ & 0 & 3 & 2 & 3 & 1 & 3 & 1 & 3 & 0 & 3 & 0 & 3
\end{tabular}

$\begin{array}{lllllllllllll}\begin{array}{l}4 \text { "almost all } \\ \text { the time" }\end{array} & 2 & 0 & 2 & 0 & 0 & 0 & 0 & 0 & 0 & 0 & 0 & 0\end{array}$

\section{Severity}

$\begin{array}{lllllllllllll}1 \text { "did not } & 0 & 1 & 1 & 1 & 1 & 1 & 0 & 1 & 0 & 1 & 0 & 1\end{array}$
have"

$\begin{array}{lllllllllllll}2 \text { "a little } & 6 & 6 & 15 & 6 & 8 & 6 & 9 & 6 & 4 & 6 & 4 & 6\end{array}$

\begin{tabular}{lllllllllllll}
3 "bad" & 1 & 2 & 3 & 2 & 3 & 2 & 3 & 2 & 0 & 2 & 1 & 2 \\
\hline 4 "very bad" & 2 & 1 & 3 & 1 & 0 & 1 & 0 & 1 & 0 & 1 & 0 & 1 \\
\hline Interference & & & & & & & &
\end{tabular}

\begin{tabular}{lllllllllllll}
\hline 1 "not at all" & 2 & 4 & 4 & 4 & 5 & 4 & 5 & 4 & 2 & 4 & 0 & 4 \\
\hline 2 "some" & 5 & 5 & 15 & 15 & 6 & 5 & 6 & 5 & 2 & 5 & 5 & 5 \\
\hline 3 "a lot" & 0 & 1 & 2 & 1 & 1 & 1 & 1 & 1 & 0 & 1 & 0 & 1 \\
\hline $\begin{array}{l}\text { 4 "a whole } \\
\text { lot" }\end{array}$ & 2 & 0 & 1 & 0 & 0 & 0 & 0 & 0 & 0 & 0 & 0 & 0
\end{tabular}

Table 6 Multivariable logistic regression model

\begin{tabular}{|lllll} 
Variable & Adjusted Odds ratio & Lower & Upper & P Value \\
\hline Probe 4 Any Del \& Probe 2 increased & 3.342 & 1.123 & 9.947 & 0.0301 \\
\hline Age 12years or above & 7.600 & 2.393 & 24.143 & 0.0006 \\
\hline Black or AA & 0.372 & 0.116 & 1.198 & 0.0976 \\
\hline
\end{tabular}

Note. Race and age were controlled. 


\section{Supplementary Files}

This is a list of supplementary files associated with this preprint. Click to download.

- Zofransupplementarydata.docx 